\title{
Diurnal temperature range over Europe between 1950 and 2005
}

\author{
K. Makowski, M. Wild, and A. Ohmura \\ Institute for Atmospheric and Climate Science, ETH Zurich, Zurich, Switzerland \\ Received: 6 March 2008 - Published in Atmos. Chem. Phys. Discuss.: 9 April 2008 \\ Revised: 13 June 2008 - Accepted: 30 September 2008 - Published: 13 November 2008
}

\begin{abstract}
It has been widely accepted that diurnal temperature range (DTR) decreased on a global scale during the second half of the twentieth century. Here we show however, that the long-term trend of annual DTR has reversed from a decrease to an increase during the 1970s in Western Europe and during the 1980s in Eastern Europe. The analysis is based on the high-quality dataset of the European Climate Assessment and Dataset Project, from which we selected approximately 200 stations covering the area bordered by Iceland, Algeria, Turkey and Russia for the period 1950 to 2005. We investigate national and regional annual means as well as the pan-European mean with respect to trends and reversal periods. 17 of the 24 investigated regions including the pan-European mean show a statistical significant increase of DTR since 1990 at the latest. Of the remaining 7 regions, two show a non-significant increase, three a significant decrease and two no significant trend. Changes in DTR are affected by both surface shortwave and longwave radiation, the former of which has undergone a change from dimming to brightening in the period considered. Consequently, we discuss the connections between DTR, shortwave radiation and sulfur emissions which are thought to be amongst the most important factors influencing the incoming solar radiation through the primary and secondary aerosol effect. We find reasonable agreement between trends in $\mathrm{SO}_{2}$ emissions, radiation and DTR in areas affected by high pollution. Consequently, we conclude that the trends in DTR could be mostly determined by changes in emissions and the associated changes in incoming solar radiation.
\end{abstract}

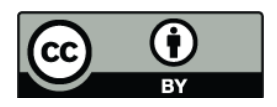

Correspondence to: $\mathrm{K}$. Makowski (makowski@env.ethz.ch)

\section{Introduction}

Satellite and ground based measurements for Europe show that the mean surface air temperature has increased overall during the second half of the last century (Trenberth et al., 2007). For the 1950s and 1960s, a characteristic phase of roughly no increase or even decrease is apparent. Since the late 1970s an accelerated increase in the mean temperature was observed. The slow increase of the mean temperature followed by a rapid increase is especially evident during the summer months (Trenberth et al., 2007) where the incoming shortwave radiation is one of the most dominant factors for the daily temperature development. This leads to the hypothesis that changes in the incoming solar flux at the surface had a discernible influence on the mean temperature development between 1950 and 2000 (Wild et al., 2007). Measurements of shortwave radiation at the surface, from stations around the globe, have shown that the incoming flux has significantly decreased and subsequently increased in many of the investigated stations within the last 4 to 5 decades (Ohmura and Lang 1989, Gilgen et al., 1998, Liepert and Kukla, 1997; Stanhill and Cohen, 2001; Roderick and Farquhar, 2002; Pinker et al., 2005; Wild et al., 2005).

The diurnal temperature range (DTR) is considered a suitable measure to investigate the counteracting effects of longwave and shortwave radiative forcing, because the diurnal minimum is closely related to the longwave radiative flux, while the diurnal maximum is predominantly determined by shortwave radiation (Fig. 1a). It is known that the DTR has been decreasing since the 1950s on a global scale due to a strong increase of the diurnal minimum (Karl et al., 1984, 1993; Kukla and Karl, 1993). Comparison of GCM simulations with observations have shown that the DTR decrease has been underestimated due to a strong increase in the modeled maximum temperature (Braganza et al., 2004). The change in DTR has formerly been addressed mainly as consequence of cloud cover development, precipitation,

Published by Copernicus Publications on behalf of the European Geosciences Union. 
a)

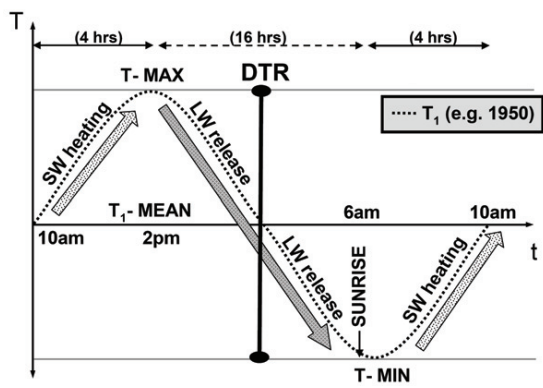

b)

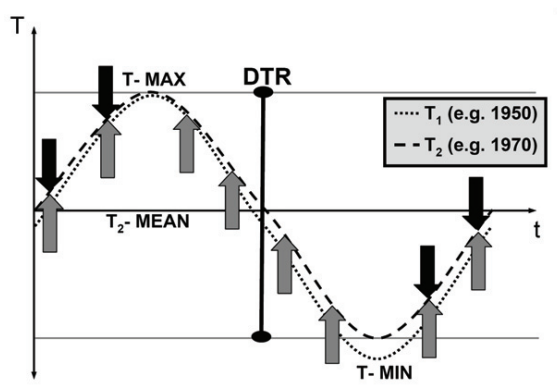

c)

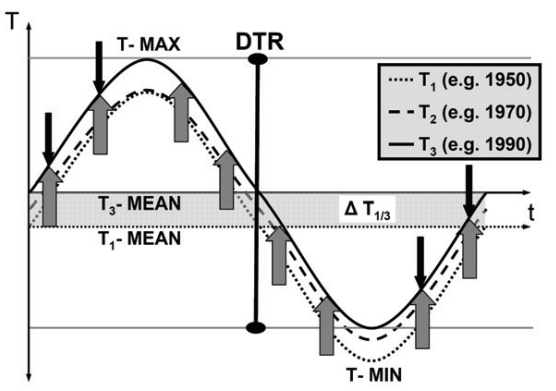

Fig. 1. Sketch of mean diurnal temperature $(T)$ cycle under (a) weak anthropogenic radiative influence, dominant radiative processes are denoted by arrows, (b) enhanced shortwave radiative cooling - "global dimming" (represented by the black arrows) and long-wave radiative warming (represented by the grey arrows), and (c) weakening shortwave radiative cooling - "global brightening" (thinner black arrows) and continued long-wave radiative warming. (DTR: diurnal temperature range; T-MAX/-MIN: daily mean maximum/minimum; T-MEAN: daily mean temperature, SW: shortwave, LW: longwave, $\Delta T_{1 / 3}$ : overall amount of warming from state (a) to (c) or e.g. 1950 to 1990 respectively).

change in irrigation and surface albedo or water vapor feedback (Stenchikov and Robock, 1995; Easterling et al., 1997; Dai et al., 1997, 1999; Stone and Weaver, 2002; Vose et al., 2005; Engelhart and Douglas, 2005). Many of the cited publications have concluded that neither of these factors alone is likely to be the unique explanation of the observed changes in DTR (Easterling et al., 1997). We argue that shortwave radiation directly or via feedbacks is a major factor for the changes in DTR since only the shortwave radiation - modulated by the atmospheric aerosol burden - could exert a strong and sufficiently homogeneous effect to change DTR on a global scale (Liu et al., 2004; Wild et al., 2007).

The decrease of the solar flux and its relative cooling effect can been seen as a blocking action against the increase of temperature caused by the greenhouse effect. Consequently the diurnal maximum temperature remains constant while the diurnal minimum is forced to increase (Fig. 1b). The recovery of surface solar radiation results in a removal of the blocking on diurnal temperature development thus leading to an increase of DTR and daily maximum respectively, thereby revealing the full extent of global warming (Wild et al., 2007) (Fig. 1c).

In the present study a detailed investigation of this issue is conducted focusing on the European area where the best coverage with observational data can be found.

\section{Data and methods}

We chose the data products of the European Climate Assessment and Dataset Project (ECA\&D-P) for an internally consistent investigation of the DTR evolution during the recent decades. It contains freely available data for more than 600 stations with minimum and maximum temperature measurements in daily resolution for different periods between about 1800 and today (Klein Tank et al., 2002).
Because the change of incoming radiative flux at the surface is considered very important to DTR development and is measured since the 1950s, the complete second half of the last century is investigated in this study. From the ECA\&D$P$ dataset, all stations with data for the period 1951 up to 2003 (or up to 2005 where available) were selected and national means were calculated. The time series of a station was dismissed if it had more than five years with data gaps or if two or more consecutive years were affected by these gaps. In addition, each time series was checked for jumps in the DTR. If jumps of more than half degree were caused by filled data (from neighboring stations, performed during ECA\&D-P), then the value was replaced by an interpolated value, on monthly basis, if the measurement from the original site was available in the previous and following year. In total less than $0.5 \%$ of the monthly values used in this study were interpolated due to missing data. Systematic errors probably due to data submission were found in all stations in Iceland, Denmark and Romania. For Iceland all data after 1998, for Denmark all data after 2002 and for Romania all data had to be discarded and these were replaced by data which we obtained directly from the respective national meteorological service. For the region of the former Republic of Yugoslavia (FRY) all data prior to 1956 had to be dismissed due to quality issues. For Poland, data are available only since 1966. The temporal coverage was still considered sufficient to investigate decadal changes in DTR.

To obtain a sufficient number of stations for the calculation of regional annual means (Fig. 2), station measurements were grouped either nationally or by averaging over several small nations. Netherlands, Luxembourg and Belgium were drawn together as BeNeLux, likewise the states of the FRY; Estonia, Lithuania and Latvia were grouped as Baltic States, Slovakia and the Czech Republic to former Czechoslovakia (FCZS).

Conversely, Germany was divided into an eastern and a western part according to the border line from the pre-1989 

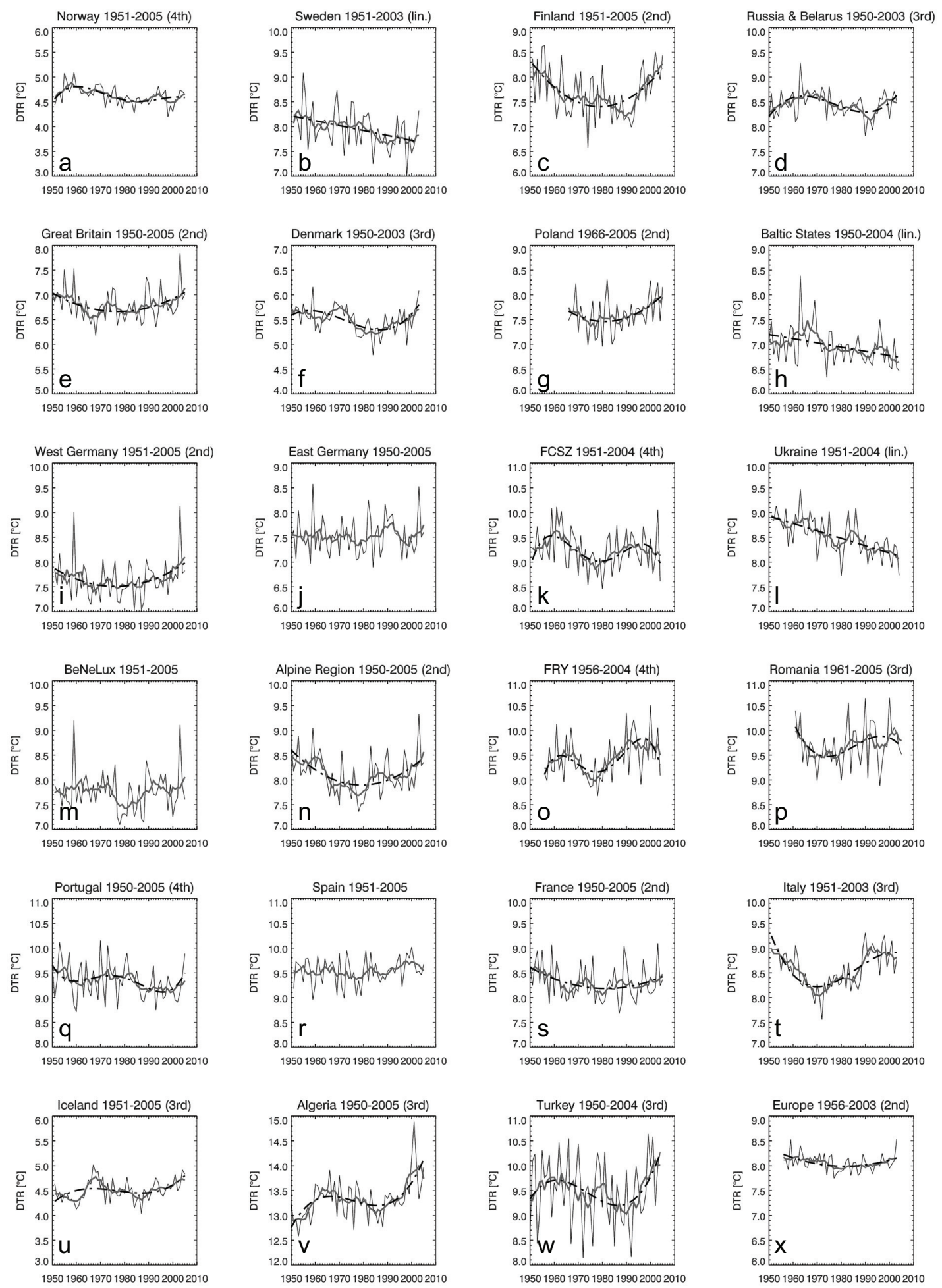

Fig. 2. Time series of annual mean DTR for each investigated region. All y-axes are scaled to 3 degrees Celsius for a better comparability. Graphs are geographically arranged - except: surrounding regions of Europe as well as European mean are in the last row. The order of the best suitable polynomial trend model according to Table 1 is indicated in brackets next to the name of the region and the investigated period. Thick, grey, solid line presents 7 year running mean. The thick, black, dashed line shows the fitted trend model, if no black line is plotted none of the models was significant above the 90\% level.FCZS - former Czechoslovakia, FRY - Former Republic of Yugoslavia. 


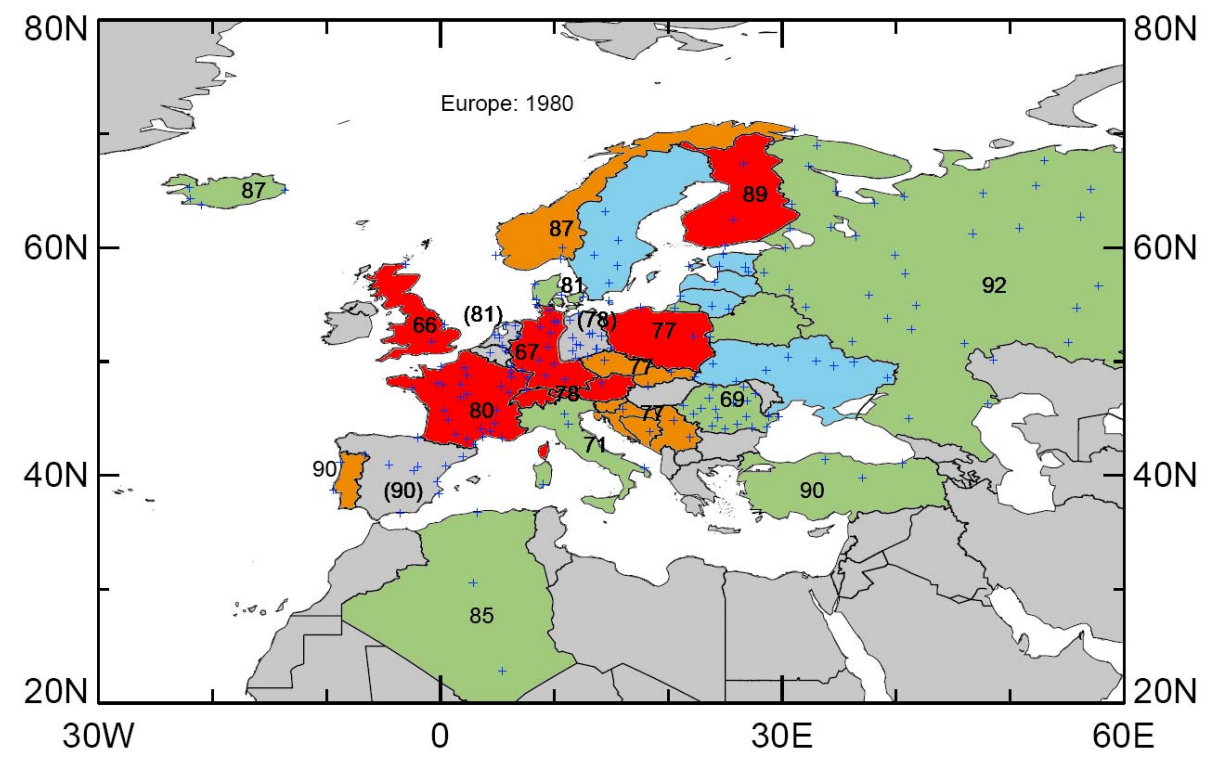

Fig. 3. Distribution of statistical significant, fitted DTR trend models. Blue - linear (all trends are negative), red - second order (all trends show first a decrease, then an increase), green - third order (all trends show first an increase, then a decrease, then an increase) orange forth order polynomial. Numbers are the year of reversal from decrease to increase in the 7 year running mean, derived from the annual mean DTR of region/country where denoted. The uncertainty of the actual year of reversal can be inferred from Fig. 4 . The trend model is not significant $(>90 \%)$ if the numbers are in brackets, consequently the investigated region is also not color-coded (Spain, Eastern-Germany, Benelux). Blue crosses represent stations investigated.

period. This is to take account of the different development of atmospheric aerosol burden in the two countries, which depends mainly on the industrial emissions within the range of some tens to hundreds of kilometers upstream. The overall resulting data coverage is indicated by the small blue crosses shown in Fig. 3, identifying 189 (168 with coverage 19562003) out of the original 604 ECA\&D-P stations satisfying the criteria described above.

Subsequently these national annual mean time series were fitted by polynomials up to fourth order, to facilitate the characterization and quantification of the DTR trend (Fig. 2). The rational for fitting polynomial trend models was investigated by applying multiple regression analysis and control of lagged autocorrelation within the residuals to assure stationary white noise. The regression analysis, followed by calculation of statistical significance level ( 1 - P-values; given in $\%$ ) based on a standard T-test was performed for every coefficient for fits between first order (linear) and fourth order polynomials as summarized in Table 1 (for further details see reading example, Appendix A1).

For most regions $R^{2}$ increased together with the statistical significance of the fitted model, hence making it easy to decide which of the investigated models performs best. If the comparison of $R^{2}$ and p-values (significance levels) showed an ambiguous result (see e.g. Table 1, line 5, Denmark), the residuals were checked in more detail and the model with the lowest autocorrelations in the residuals was selected (not shown). Note that only models with no significant autocor- relations were accepted. The annual mean time series together with the fitted trend curve and the seven year running mean trend for all investigated regions as well as the European mean are shown in Fig. 2.

Further information for each time series was obtained by estimating the year of reversal from decreasing to increasing DTR (applies not to regions with linear trends). The estimation was performed by calculating the minimum in the seven year running mean (Fig. 2) for the period 1965 to 1995 . For the example of Finland (Fig. 2c), the running mean given as gray bold line shows a clear local minimum in 1989 (compare year given in Fig. 3 and diamond at the row "Finland" in Fig. 4). The particular period 1965 to 1995 was chosen since it embraces the whole era of reversal from dimming to brightening (Wild et al., 2005). The results are presented in Fig. 3 and Fig. 4. The numbers displayed in Fig. 3 give the year of the minimum of DTR. If they are printed in brackets no significant trend could be estimated (compare Table 1).

In addition to the minimum DTR value between 1965 and 1995, all values within the lowest $10 \%$ of the difference between maximum and minimum (7 year running mean) value within that period have been calculated to give additional information on the distinctness of the reversal. In Fig. 4 the years below and equal to the 10th-percentile are marked with dashes, diamonds show the minimum (for further details on the method see detailed example, Appendix A2). 
Table 1. Data for each investigated region, including overall Europe and each trend type. Order: Western Europe N-S; Eastern N-S, surrounding regions, Europe; Columns from left to right: (1) Name of the region, (2) $R^{2}$ and significance codes for each coefficient (-: $<90 \%$, o: $90 \%-95 \%$, x: $95 \%-99 \%$, xx: 99\%-99.999\%, xxx: >99.999\%), columns (3) to (5) equal to column (2) but for higher order polynomial fits, (6) number of stations for the mean calculations, and (7) data period (for more details see example in Appendix A1). $R^{2}$ 's in bold denote the best suitable model according to $R^{2}$, significance and residuals (not shown), which was subsequently used in Fig. 2 . FCZS - former Czechoslovakia, FRY - Former Republic of Yugoslavia.

\begin{tabular}{|c|c|c|c|c|c|c|c|c|c|c|}
\hline & $1 \mathrm{st}$ & & 2nd & & $3 \mathrm{rd}$ & & 4 th & & No. & Period \\
\hline Norway & 0.15 & $\mathbf{x x}$ & 0.17 & - & 0.26 & $\begin{array}{l}\mathbf{0} \\
\mathbf{x} \\
\mathbf{x}\end{array}$ & 0.32 & $\begin{array}{l}\mathbf{x} \\
\mathbf{x} \\
\mathbf{x} \\
\mathbf{0}\end{array}$ & 4 & $51-05$ \\
\hline Sweden & 0.15 & $\mathbf{x x}$ & 0.15 & - & 0.16 & $\begin{array}{l}- \\
- \\
-\end{array}$ & 0.20 & $\begin{array}{l}- \\
- \\
-\end{array}$ & 5 & $51-03$ \\
\hline Finland & 0.01 & - & 0.25 & $\begin{array}{l}\mathbf{X X X} \\
\mathbf{X X X}\end{array}$ & 0.27 & $\begin{array}{l}- \\
- \\
-\end{array}$ & 0.28 & $\begin{array}{l}- \\
- \\
-\end{array}$ & 3 & $51-05$ \\
\hline Great Britain & $<0.01$ & - & 0.14 & $\begin{array}{l}\mathbf{x x} \\
\mathbf{x x}\end{array}$ & 0.14 & $\begin{array}{l}- \\
- \\
-\end{array}$ & 0.14 & $\begin{array}{l}- \\
- \\
-\end{array}$ & 3 & $50-05$ \\
\hline Denmark & 0.06 & $\mathbf{o}$ & 0.18 & $\begin{array}{l}\mathbf{x x} \\
\mathbf{x}\end{array}$ & 0.30 & $\begin{array}{l}- \\
\mathbf{x} \\
\mathbf{x x}\end{array}$ & 0.33 & $\begin{array}{l}- \\
- \\
-\end{array}$ & 5 & $50-03$ \\
\hline East Germany (DDR) & $<0.01$ & - & $<0.01$ & - & $<0.01$ & $\begin{array}{l}- \\
-\end{array}$ & $<0.01$ & $\begin{array}{l}- \\
- \\
-\end{array}$ & 12 & $50-05$ \\
\hline West Germany (BRD) & $<0.01$ & - & 0.12 & $\begin{array}{l}\mathbf{x} \\
\mathbf{x}\end{array}$ & 0.12 & $\begin{array}{l}- \\
-\end{array}$ & 0.12 & $\begin{array}{l}- \\
- \\
-\end{array}$ & 13 & $51-05$ \\
\hline BeNeLux & $<0.01$ & - & 0.02 & - & 0.04 & $\begin{array}{l}- \\
- \\
-\end{array}$ & 0.06 & $\begin{array}{l}- \\
- \\
-\end{array}$ & 9 & $51-05$ \\
\hline Alpine & 0.01 & - & 0.24 & $\begin{array}{l}\mathbf{x x x} \\
\mathbf{x x x}\end{array}$ & 0.25 & $\begin{array}{l}- \\
-\end{array}$ & 0.25 & $\begin{array}{l}- \\
- \\
-\end{array}$ & 2 & $50-05$ \\
\hline France & 0.02 & - & 0.11 & $\begin{array}{l}\mathbf{x} \\
\mathbf{x}\end{array}$ & 0.11 & $\begin{array}{l}- \\
-\end{array}$ & 0.11 & $\begin{array}{l}- \\
- \\
-\end{array}$ & 25 & $50-05$ \\
\hline Italy & 0.03 & - & 0.42 & $\begin{array}{l}\mathbf{X X X} \\
\mathbf{X X X}\end{array}$ & 0.52 & $\begin{array}{l}\mathbf{x x x} \\
\mathbf{X X x} \\
\mathbf{x x}\end{array}$ & 0.59 & $\begin{array}{l}- \\
- \\
\mathbf{x} \\
\mathbf{x x}\end{array}$ & 4 & $51-03$ \\
\hline Spain & 0.02 & - & 0.05 & - & 0.05 & $\begin{array}{l}- \\
- \\
-\end{array}$ & 0.08 & $\begin{array}{l}- \\
- \\
-\end{array}$ & 9 & $51-05$ \\
\hline Portugal & 0.05 & $\mathbf{o}$ & 0.05 & - & 0.06 & $\begin{array}{l}- \\
- \\
-\end{array}$ & 0.12 & $\begin{array}{l}- \\
\text { o } \\
\text { o } \\
\text { o }\end{array}$ & 3 & $50-05$ \\
\hline
\end{tabular}


Table 1. Continued.

\begin{tabular}{|c|c|c|c|c|c|c|c|c|c|c|}
\hline & $1 \mathrm{st}$ & & 2nd & & $3 \mathrm{rd}$ & & 4th & & No. & Period \\
\hline Russia \& Belarus & 0.02 & - & 0.02 & - & 0.22 & $\begin{array}{l}\mathbf{x x} \\
\mathbf{x x x} \\
\mathbf{x X x}\end{array}$ & 0.22 & $\begin{array}{l}- \\
- \\
-\end{array}$ & 36 & $50-03$ \\
\hline Baltic States & 0.13 & $\mathbf{x x}$ & 0.15 & - & 0.16 & $\begin{array}{l}- \\
- \\
-\end{array}$ & 0.17 & $\begin{array}{l}- \\
- \\
-\end{array}$ & 9 & $50-04$ \\
\hline Poland & 0.07 & $\mathbf{o}$ & 0.17 & $\begin{array}{l}\mathbf{0} \\
\mathbf{x}\end{array}$ & 0.17 & $\begin{array}{l}- \\
- \\
-\end{array}$ & 0.17 & $\begin{array}{l}- \\
- \\
-\end{array}$ & 2 & $66-05$ \\
\hline FCZS & 0.02 & - & 0.03 & - & 0.04 & $\begin{array}{l}- \\
-\end{array}$ & 0.16 & $\begin{array}{l}\mathbf{x} \\
\mathbf{x x} \\
\mathbf{x x} \\
\mathbf{x}\end{array}$ & 3 & 51-04 \\
\hline Ukraine & 0.37 & $\mathbf{x x x}$ & 0.37 & - & 0.37 & $\begin{array}{l}- \\
-\end{array}$ & 0.37 & $\begin{array}{l}- \\
- \\
-\end{array}$ & 9 & $51-05$ \\
\hline FRY & 0.08 & $\mathbf{x}$ & 0.11 & - & 0.13 & $\begin{array}{l}- \\
- \\
-\end{array}$ & 0.26 & $\begin{array}{l}\mathbf{x} \\
\mathbf{x} \\
\mathbf{x x} \\
\mathbf{x x}\end{array}$ & 4 & $56-04$ \\
\hline Romania & 0.01 & - & 0.05 & - & 0.13 & $\begin{array}{l}\mathbf{x} \\
\mathbf{x} \\
\mathbf{0}\end{array}$ & 0.16 & $\begin{array}{l}- \\
- \\
- \\
-\end{array}$ & 19 & $61-05$ \\
\hline Iceland & 0.07 & $\mathbf{o}$ & 0.07 & - & 0.18 & $\begin{array}{l}\mathbf{x} \\
\mathbf{x} \\
\mathbf{x}\end{array}$ & 0.22 & $\begin{array}{l}- \\
- \\
-\end{array}$ & 4 & $51-05$ \\
\hline Algeria & 0.17 & $\mathbf{x x}$ & 0.19 & - & 0.37 & $\begin{array}{l}\mathbf{x x} \\
\mathbf{x x x} \\
\mathbf{x x x}\end{array}$ & 0.37 & $\begin{array}{l}0 \\
- \\
- \\
-\end{array}$ & 3 & $50-05$ \\
\hline Turkey & $<0.01$ & - & 0.04 & - & 0.13 & $\begin{array}{l}- \\
\mathbf{o} \\
\mathbf{x}\end{array}$ & 0.13 & $\begin{array}{l}- \\
- \\
-\end{array}$ & 3 & $50-04$ \\
\hline Europe & 0.01 & - & 0.14 & $\begin{array}{l}\mathbf{x} \\
\mathbf{x}\end{array}$ & 0.21 & $\begin{array}{l}- \\
- \\
\text { o }\end{array}$ & 0.21 & $\begin{array}{l}- \\
- \\
-\end{array}$ & 168 & $56-03$ \\
\hline
\end{tabular}

\section{Results}

In the following section we discuss annual means of the DTR records, starting with the regional averages as described above, followed by a description of the European mean. The data records and polynomial fits determined in this analysis are compiled in Fig. 2.
By the use of regional averages we aim to underline the hypothesis that DTR is affected by changes in regional emissions influencing shortwave radiation reaching the ground. Detailed information for each country or region can be found in Table 1 and Figs. 2-4. A complete description of all regions (except the European mean, see below) shown in Fig. 2 is provided in Appendix B. 
For most of Western Europe a distinct reversal from decreasing to increasing DTR is visible. The fitted polynomial trends are significant in the Great Britain, Germany, Poland, Finland, France, Italy and Switzerland/Austria. For Spain and the Benelux an alike development of decrease and increase in DTR can be seen from the running mean but the fitted polynomial trends miss the $90 \%$ significance level.

Circumjacent countries, as Portugal, FRY, FCZS and Norway show trends significant at the fourth order polynomial with pronounced periods of increasing DTR in recent decades. In North-Eastern Europe a region covering Sweden, the Baltic States and the Ukraine, with a continued decrease in DTR can be identified. All decreasing linear trends are significant at the $99 \%$ level.

The countries located farther away from central Europe, namely Russia, Belarus, Turkey, Algeria and Iceland show trends which are best described by a third order polynomial. All coefficients for all trends are significant at the 95\% level except for the first (not significant) and second coefficient (90\% level) of Turkey. In addition to the presently increasing DTR a prominent feature in the annual mean time series of the above mentioned countries is a second, earlier increase in DTR between 1950 and 1960 which is addressed in more detail in the discussion section.

Overall, the farther away the country is located from central Europe the more recent is the time of reversal from decrease to increase of DTR. The earliest can be found in the UK (1967) and Germany (1967), the latest in Iceland (1987), Turkey (1990) and Russia (1992). From Fig. 4 extended periods of reversal can be seen in Romania, Norway and Denmark. For Romania, which is an outlier compared to the surrounding nations, the early appearing of the lowest value in the 7 year running mean is put more into perspective by the "error bars" in Fig. 4, equally true for the late reversal in Norway and the early one in Denmark.

For the European geographical mean between 1956 and 2003, 168 stations were used. To avoid biases, series shorter than this period have been excluded. The European trend is best described by a second order polynomial (Fig. 2x). Both coefficients are significant at the $95 \%$ level. The reversal from decrease to increase takes place in the early 1980s. This overall character of the averaged European DTR is even strengthened if shorter data series such as those from Romania and Poland were included (alternative mean not shown).

\section{Discussion}

The extent of the DTR is determined by many different factors, such as surface solar radiation or sunshine duration, cloud cover connected with changes in large scale circulation or aerosols, soil moisture and water vapor content of the atmosphere.

Change in water vapor for example leads to an asymmetry in the DTR (Stenchikov and Robock, 1995) by changing

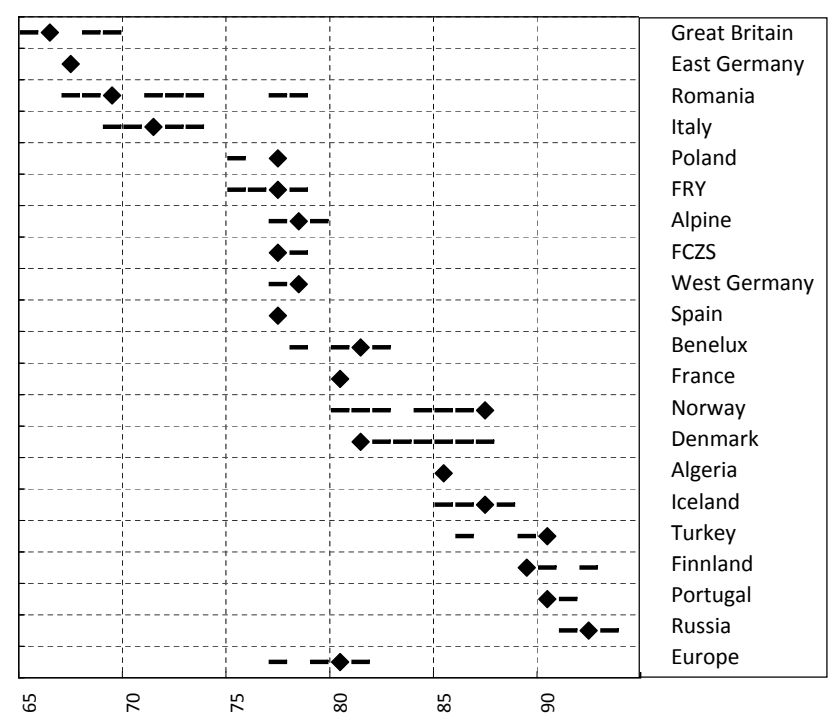

Fig. 4. Reversal of 7 year running mean DTR trends. Diamonds represent the year of reversal of DTR as calculated from 7 year running mean trend. Dashed lines show additionally the period covered by values within the lowest $10 \%$ of the amplitude of maximum DTR minus minimum DTR (of seven year running mean values) for the period 1965-1995. For more details see example in Appendix A2. FCZS - former Czechoslovakia, FRY - Former Republic of Yugoslavia.

longwave and shortwave downwelling fluxes. A continued increase in water vapor due to anthropogenic influence would lead to a slightly reduced downwelling shortwave and increased downwelling longwave radiation at the surface. This would consequently lead to a continued reduction of DTR which, however, we did not observe in the investigated area, and therefore do not consider water vapor as a major factor influencing DTR in Europe.

Soil moisture plays an important role by damping the DTR as energy is consumed by evaporation during the daytime and released by condensation during the nighttime. However, according to Robock and $\mathrm{Li}$ (2006), long-term changes in soil moisture are coupled to changes in solar radiation and tropospheric air pollution respectively at least on regional scale in Russia and the Ukraine, where long-term records of soil moisture data are available.

For the inter-annual variability of DTR the total amount of cloud cover as well as the cloud optical properties play an important role again by altering longwave and shortwave downwelling fluxes (Karl et al., 1993). Clouds alter DTR mostly by damping the daytime maximum via a strong reduction of surface solar radiation, while the influence on the nighttime minimum seems to be rather small (Dai et al., 1999). Apart from local convection, long-term changes in cloud cover can be connected to large scale circulation patterns and aerosols. However, the correlation between DTR and cloud cover in Europe for the period 1910 to 1990 is only 0.35 according to Dai et al. (1997). 
For the long-term influence of changes in large scale circulation Sanchez-Lorenzo et al. (2008) show that in Western Europe on a seasonal scale, circulation may have an influence on the long-term development of sunshine duration, which can be used as proxy for surface solar radiation (Stanhill and Cohen, 2005). Still for the overall annual mean long-term trend in sunshine duration, they identified changes in surface solar radiation from anthropogenic aerosol emissions as a more likely explanation.

To sum up, factors influencing surface solar radiation and factors that are influenced by surface solar radiation seem to account for the most of the changes in DTR in Europe. Consequently, we consider changing surface solar radiation as a major cause for the different types of DTR development.

Since solar radiation incident at the top of atmosphere has not changed substantially during the investigated period (Beer et al., 2000), two different candidates are likely to have influenced surface shortwave radiation, namely clouds and aerosols (first and secondary effect). Norris and Wild (2007) showed that by removing the cloud cover influence from surface solar radiation data, the reversal from dimming to brightening becomes even more pronounced for most of Europe. Consequently cloud coverage changes acted as a disguise rather than a cause for the variations in surface solar radiation.

A much more likely candidate for the varying surface solar radiation and DTR trend types and their time shifted reversals are different patterns of emissions, leading to regionally differentiated backscattering of solar radiation by aerosols. A reduction of incoming radiation has been reported by Liepert and Kukla (1997), Gilgen et al. (1998) and Abakumova et al. (1996). Wild et al. (2005) reported a reversal from global dimming to brightening in mid to late 1980s at widespread locations throughout the world. From Abakumova et al. (1996), a reduction in incoming shortwave radiation until at least 1990 is evident for the specific region of Russia. These results indicate that changes in surface solar radiation were found in many regions though they do not have to be necessarily simultaneous. The global background signal and forcing from aerosol as presented by Mishchenko et al. (2007), showing a general decrease during the 1990s, can be dominated by local influence as described by Alpert et al. (2005). Publications from Stern (2006) and Lefohn et al. (1996) assume that a reversal from increase to decrease of Eastern European emissions (dominated by Russia) takes place in the late 1980s or early 1990s. In contrast, Western European emissions are peaking already during the early 1970s according to Smith et al. (2004), Streets et al. (2006) and Stern (2006). This is confirmed in Mylona (1996) and Vestreng et al. (2007) who have shown that the maximum in $\mathrm{SO}_{2}$ emissions from fossil fuel for early industrialized countries, such as the UK or the former Federal Republic of Germany, can be as early as the second half of the 1960s.
4.1 DTR, radiation and emissions - the biggest European emitters

In the following section we discuss the qualitative connection between trends in $\mathrm{SO}_{2}$ emissions, sunshine duration, radiation and DTR in several examples. We included the annual sunshine duration in this section as a proxy for surface solar radiation (Stanhill and Cohen, 2005), which is only available for a sufficient number of sites since the 1960s. SanchezLorenzo et al. (2007 and 2008) provide data for sunshine duration in Western Europe between 1938 and 2004. $\mathrm{SO}_{2}$ emissions at land level are available from Mylona (1996) and Vestreng et al. (2007). Vestreng et al. (2007) is partially a succeeding work of Mylona (1996) and both provide $\mathrm{SO}_{2}$ emission estimates for every fifth year. Therefore, we combined the estimates to one time series if they cover the same source region. Data from Mylona (1996) are available between 1880 and 1990, Vestreng et al. (2007) provide data between 1980 and 2004. For the overlapping period between 1980 and 1990 the data from Vestreng et al. (2007) were favored for the following analysis. Further $\mathrm{SO}_{2}$ estimates can be derived from Lefohn et al. (1996). They provide annual estimates of sulfur emissions between 1850 and 1990. Obviously not all sulfurous emissions will be in the form of $\mathrm{SO}_{2}$ but still we converted all sulfur into $\mathrm{SO}_{2}$ for the gain of a much simpler comparison against the Mylona (1996) and Vestreng et al. (2007) data. Valuable information on transboundary fluxes and trend development of $\mathrm{SO}_{2}$ since 1980 can be obtained from Klein and Benedictow (2006). Data from long-term surface solar radiation measurement can be found in Ohmura (2006). A recently submitted paper from Gilgen et al. (2008) provides additional information on reversal years and overall trends from gridded data of the Global Energy Balance Archive. To make the characteristics of the DTR time series more easily comparable against the rather slow changes of emissions and the low pass filter data of sunshine duration, we calculated the eleven year running mean of the annual DTR time series. The miss weighting at the edges was indicated by using dashed lines (Figs. 5 and 6). The emissions of $\mathrm{SO}_{2}$ were plotted upside down to indicate the potential sulfate aerosol forcing on DTR.

According to Berge et al. (1999) the 10 biggest emitters (in total t/a) in Europe are: Bulgaria, France, Germany, Italy, Poland, Spain, Great Britain, Ukraine, Russia and the Czech Republic (or FCZS). Except for Bulgaria and Italy all countries above were analyzed with respect to their DTR trends and will be discussed subsequently in more detail beginning with the Eastern European countries, from south to north.

The best fitting trend for the Ukrainian DTR time series is a linear trend with a slope of $-0.014^{\circ} \mathrm{C} / \mathrm{a}$, emphasizing a continuous decrease (Fig. 21). A more detailed inspection of the running mean in Fig. 21 and Fig. 5a reveals, however, a tendency towards an increase around 1978 which is reverses to a continued decrease from 1987 onward. Data for emissions are available from 1980 (Mylona 1996 and Lefohn et 
a)

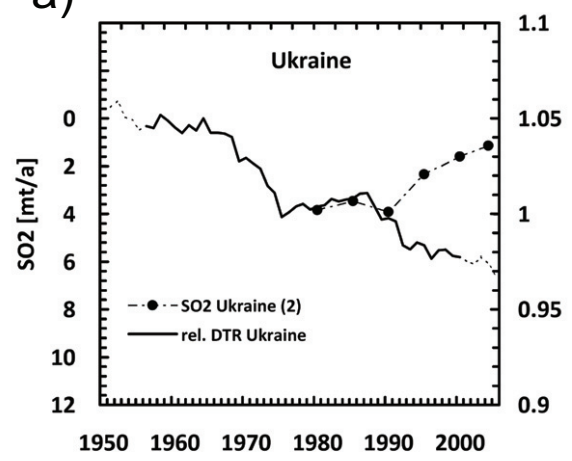

c)

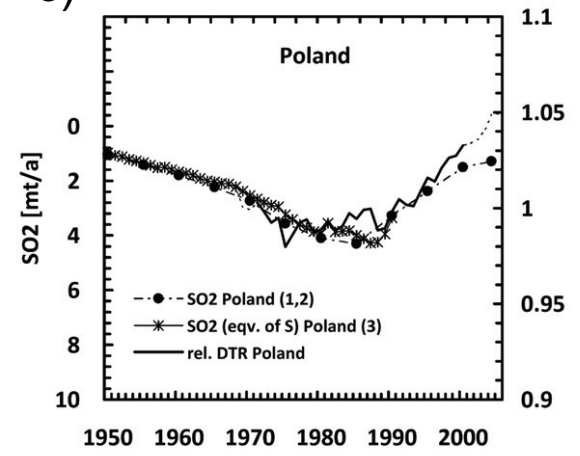

b)

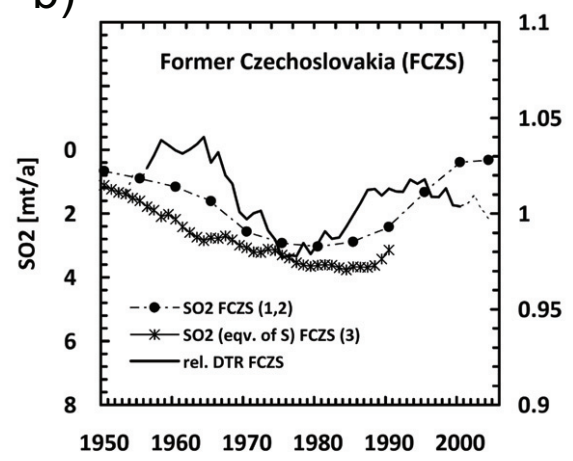

d)

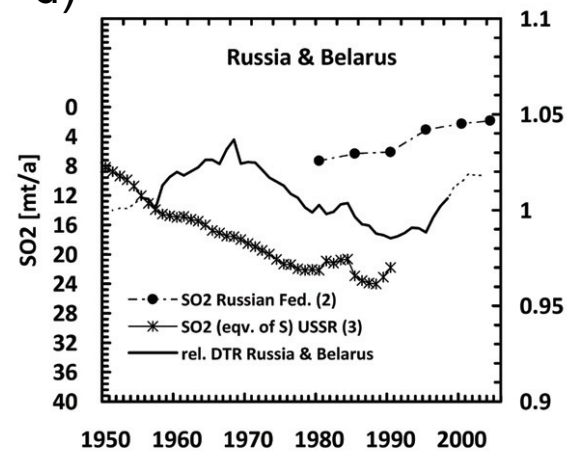

Fig. 5. Time series of annual mean DTR and $\mathrm{SO}_{2}$ emissions. Eleven-year running means of DTR, expressed as relative (rel.) deviations from the 1971-2000 mean, are plotted as solid black line. Differently weighted first and last five years of the time series are denoted as dashed black lines. $\mathrm{SO}_{2}$ emissions from Mylona (1996) (2) and Vestreng et al. (2007) (2) were plotted up side down, to indicate the presumed forcing. Estimated sulfur emissions from Lefohn et al. (1996) (3) were converted to $\mathrm{SO}_{2}$ equivalent and also plotted upside down. All $\mathrm{SO}_{2}$ estimates are expressed in megatons per year.

al., 1996 estimated their values for the Union of Soviet Socialist Republics - USSR), showing a distinct decrease since 1990 which is not reflected in the DTR data. However, the previously described short increase and decrease of DTR is reflected in a short decreasing and increasing period of $\mathrm{SO}_{2}$ emissions. Surface solar radiation measurements for Odessa show a decrease from 1960 until 1987 (end of data). The described short increase in DTR between 1978 and 1987 is mirrored as well in the radiation time series plot (Abakumova et al., 1996 (Fig. 4), most evident between 1977 and 1983. To summarize, the continued decrease in DTR since 1980 cannot be explained by a continued increase of national emissions. However, the findings are not contradictory with respect to the connection between DTR and radiation (for further details on the Ukraine, as an example for linear decreasing trends, see Sect. 4.3).

For the FCZS, data of emissions are available for the whole period from Mylona (1996) and Vestreng et al. (2007). The highest values occur around 1980 in line with the reversal of DTR from decrease to increase which is calculated around 1977 (Fig. 4 and Fig. 5b). In Gilgen et al. (2008) the reversal of surface solar radiation from dimming to brightening is estimated between 1978 and 1983.

Daily maximum and minimum temperature for Poland is available since 1966. The reversal from decrease to increase is calculated at 1977 in the seven year running mean. The running mean of the Polish time series (Fig. $2 \mathrm{~g}$ and Fig $5 \mathrm{c}$ ) shows a short increasing and subsequently decreasing period between 1975 and 1986. The reversal of the second order polynomial fit to DTR which omits the described hump is between 1980 and 1985, this is close to the peaking of emissions in 1985. Consequently, both reversals are consistent with the reversal in incoming shortwave radiation in 1980.

Russian emissions peak at 1975 according to Vestreng et al. (2007). Other emission estimates as e.g. from Stern (2006) and Lefohn et al. (1996) suggest that the decrease of emissions started much later namely in the late 1980s (Fig. 5d) with the breakdown of the former Soviet Union. However, the significant decrease of emissions after the collapse of the Eastern Bloc is reflected in all cited emission estimates. The DTR decrease for Russia lasts until 1990 consistent with the decrease in surface solar radiation 

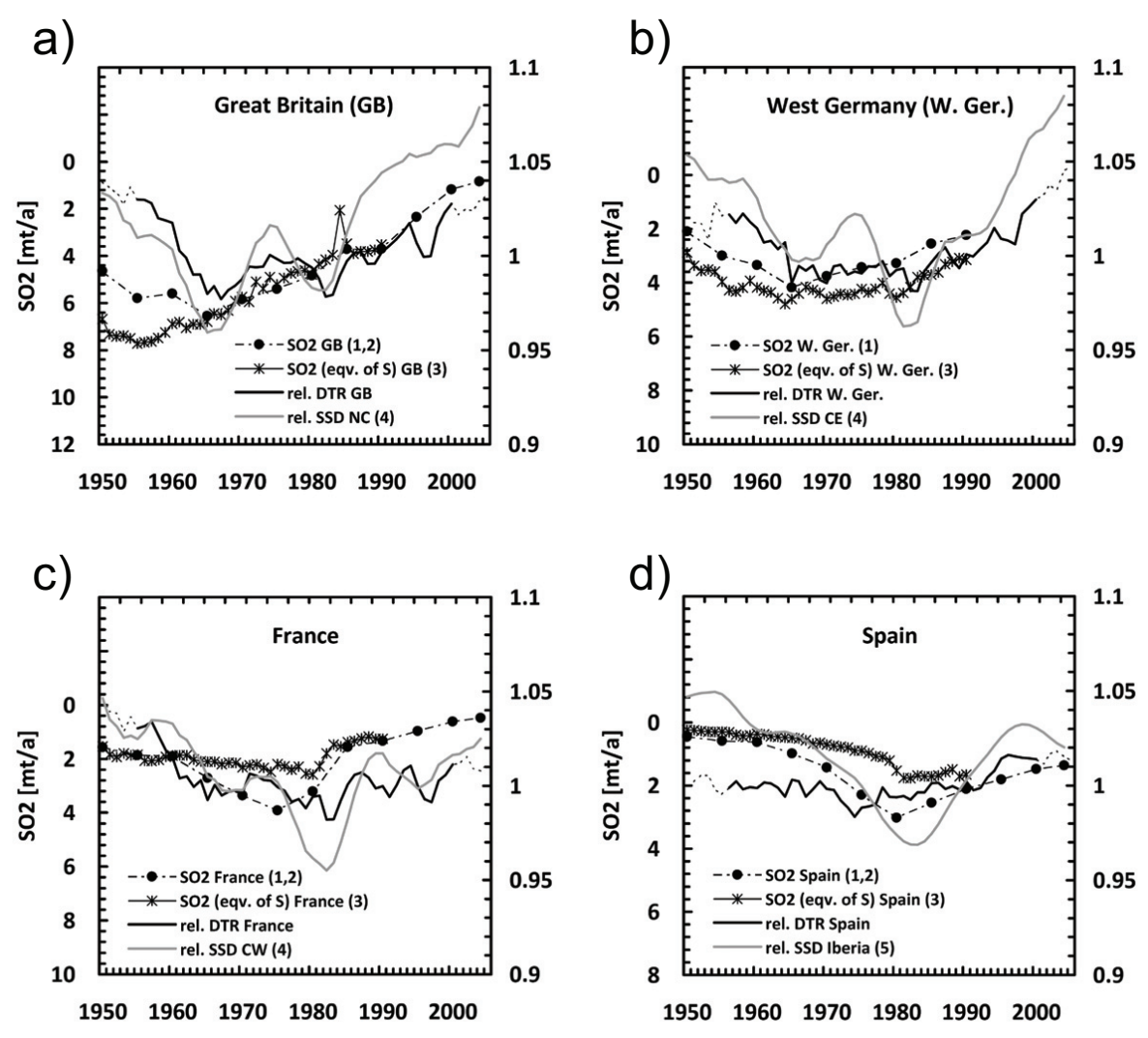

Fig. 6. As Fig. 5. In addition, sunshine duration series from Sanchez-Lorenzo et al. (2008) (4) and Sanchez-Lorenzo et al. (2007) (5) are plotted as solid grey line. Plotted data are low-pass filtered values (11-year window 3 year $\sigma$ Gaussian low-pass filter) expresses as relative deviations from the 1961-1990 mean.

(Abakumova et al., 1996) measured at Moscow. Likewise, the observed increase of surface solar radiation at Moscow (Wild et al., 2005) is mirrored in an increasing DTR. Both are potentially caused by the strong decrease of $\mathrm{SO}_{2}$ emissions reported from various estimates.

In Western Europe the biggest emitters during 1985 and 1995 are France, (West) Germany, Great Britain and Spain (Berge et al., 1999). The DTR for all four regions is best described with a second order polynomial trend, significant above $95 \%$ except for Spain with p-values of 0.35 , 1st coefficient) and 0.21 (2nd coefficient) (not shown). For the comparison of DTR against $\mathrm{SO}_{2}$ emissions and sunshine duration we used in addition the low-pass filter time-series from Sanchez-Lorenzo et al. (2007) for Iberia to compare it to our DTR data of Spain. In Sanchez-Lorenzo et al. (2008) the same authors provided annual means of sunshine duration for most of Western Europe, split into six regions. Here we also used the low pass filtered data of sunshine duration for the regions NC (north central), CW (central west) and CE (central east). We compared NC to Great Britain, CW to France and $\mathrm{CE}$ to West Germany according to their spatial coverage given in Fig. 1 of Sanchez-Lorenzo et al. (2008).
For Great Britain a reversal in DTR is apparent around 1965 simultaneously to the emissions from Mylona (1996) of $\mathrm{SO}_{2}$ which are peaking in 1965, according to Lefohn et al. (1996) emissions reach their maximum already around 1960. The annual sunshine duration from Sanchez-Lorenzo et al. (2008), which covers the central to south-eastern part of the UK, shows a reversal from decrease to increase in the late 1960s. Subsequently, sunshine duration increases along with DTR and the decreasing emissions until the present (Fig. 6a).

In the former Federal Republic of Germany, the DTR reversal is calculated at 1967 by the 7-year-running mean. Reversal of $\mathrm{SO}_{2}$ emissions is in 1965 according to Mylona (1996). The most dominant increase of DTR and decrease of $\mathrm{SO}_{2}$ respectively, however begins during the 1980s which is in line with the end of the decrease in surface solar radiation in Germany (Liepert and Kukla, 1997 (Fig. 2) and a strong increase in sunshine duration (Fig. 6b). Notably the horizontal visibility increased already since the second half of the 1960s in most of the Western German stations investigated by Liepert and Kukla (1997). These results point to a decrease of turbidity and thus a reduction of aerosol burden of the troposphere.

In France the DTR reversal is calculated at 1980 while $\mathrm{SO}_{2}$ emissions estimated by Mylona (1996) start to decrease from 
1975, Lefohn et al. (1996) in contrast determine the highest value of emissions not until 1980 (Fig. 6c). The reversal in shortwave incoming radiation is between 1980 and 1986 according to Gilgen et al. (2008). Sunshine duration reverses between 1980 and 1985 . The maximum lag of about one decade between radiation and $\mathrm{SO}_{2}$ emission (form Mylona 1996) reversals can be explained by the method used to determine the year of reversal. Gilgen et al. (2008) used a second order polynomial fit to define the period of reversal. The reversal in the DTR retrieved from the fitted second order polynomial would be similar, namely around 1980 to 1982 (Fig. 2s).

Spain as the most southern representative of the largest emitters in Europe has reduced its emissions remarkably since 1980 (Mylona, 1996). The reversal of DTR derived from the 7 year-running mean is at 1977 (Fig. 2r and Fig. 4). According to Sanchez-Lorenzo et al. (2007) the reversal for sunshine duration for the whole Iberia Peninsula is in 1982 most evident during spring and summer, with mostly clear sky situations. The period where all three independently investigated measures (namely emissions, DTR and sunshine duration) show a reversal in their long-term behavior lies consequently within 5 years (Fig. 6d).

To summarize on the section with the biggest emitters in Europe we would like to point to the good qualitative agreement between the low frequency trends in DTR and $\mathrm{SO}_{2}$ emission estimates in six (four in Western, two in Eastern Europe) of the eight regions analyzed.

The long-term evolution of sunshine duration from Sanchez-Lorenzo et al. (2007 and 2008) supports our conclusions for Western Europe. The biggest disagreement between DTR and $\mathrm{SO}_{2}$ emissions can be found for Eastern Europe, namely in Russia and the Ukraine. However, trends in surface solar radiation from Abakumova et al. (1996) for these regions support our results for long-term DTR development. To conclude that though we found good agreement, more work involving chemistry climate models with an appropriate input and transport of pollutants is required in order to improve our understanding of the relation between DTR and air pollution in the future.

\subsection{Long range effects on DTR and radiation}

According to the previous section a further feature which has to be discussed is the inconsistency in the DTR reversal compared to the reversal in emissions in a number of regions such as Finland. The running-mean curve for the DTR in Finland (Fig. 2c) shows a reversal in the early 1990s, in line with the surface solar radiation measurements, taken in Sodankyla in the north of Finland (Ohmura, 2006, Fig. 9). According to Gilgen et al. (2008) 1990 is the year of reversal from dimming to brightening, for the mean of seven stations in southern Finland. Emissions, however, peaked around 1975 (Vestreng et al., 2007). It can be seen from the EMEP (Cooperative program for monitoring and evaluation of the long- range transmission of air pollutants in Europe) Report 1/06 (Klein and Benedictow, 2006) for Finland that for 2004 about $80 \%$ of the oxidized sulphur deposition originates from outside Finland. Biggest contributor is Russia with as much as $23 \%$ for overall Finland. This implies that the influence on DTR especially for stations in the North and East of Finland is likely to be dominated by Russian emissions, thus giving a possible explanation for the reversal in DTR and surface solar radiation as late as 1989 (Fig. 4).

Similar to Finland, other countries in Northern Europe, such as Sweden, Norway, Iceland, Latvia, Lithonia and Denmark contribute no more than $10 \%$ to their total of oxidized sulphur deposition, leaving these regions as dependent on neighboring countries such as Great Britain, Germany, Poland, Estonia, Ukraine and Russia and their patterns in matters of emissions (Klein and Benedictow, 2006).

\subsection{Linear downward trends of DTR}

Another interesting feature is the linear downward trend of the DTR in Sweden, the Baltic States and Ukraine. It is noteworthy that they seem to build a north-west, south-east orientated zone between Eastern and Western Europe (Fig. 3). The linear decreasing DTR trend is not explainable by the national emission trends of the corresponding regions, since the emissions for all above mentioned countries have declined at least since 1990. Surface solar radiation for southern Sweden and the Baltic States started to increase in the late 1980s (Ohmura, 2006; Gilgen et al., 2008), subsequently DTR in both regions levels-off or increases slightly as well. However, during the 1990s DTR stopped increasing which resulted in a significant decreasing linear trend for the whole period. The continuous decrease of DTR in Ukraine cannot be explained by a continued increase of emissions. Also, no radiation data is available for further interpretation. Support for the findings on an overall decreasing DTR can be found from soil moisture measurements. Robock and Li (2006) have shown that between 1958 until the mid 1990s soil moisture increased significantly for the Ukraine. They state that precipitation and temperature alone could not have caused this development. Using a land surface model they show that a reduction in downward shortwave radiation could have caused the observed increase in soil moisture, which is in line with the DTR decrease noted above.

\subsection{Early increase in DTR and radiation}

The final feature we want to discuss in detail is the early increase of DTR during the 1950s and 1960s, visible in different regions all over Europe but mainly in the northern, eastern and the periphery regions, namely Norway, Russia, the Baltic States, FCZS, FRY as well as Iceland, Algeria and Turkey. The early increase visible from the different DTR time series might be due to an "earlier brightening" during this period. The hypothesis of an earlier brightening 
in Eastern Europe during the 1950s and 1960s is again supported by soil moisture measurement. Figure 3 of Robock and $\mathrm{Li}$ (2006) suggests that soil moisture in Russia decreased slightly between 1958 and 1970, indicating an increase in radiation.

No radiation data is available from the above mentioned regions prior to 1960. Still we can assume a similar technological development for Eastern Europe as for Western Europe but with a time shift of one to two decades as indicated by a later reversal in emissions and radiation during the period since 1960.

By investigating radiation and radiation related measurements for Western Europe prior to 1950 we can consequently find potential explanations for the observed early increase of the DTR. Evidence for an early brightening period (increase of incoming shortwave radiation) in Western Europe is presented in Ohmura (2006). The surface solar radiation data in Fig. 1 of Ohmura (2006) for Wageningen, Stockholm, Davos and Potsdam increases until the 1950s. For Wageningen this is supported from De Bruin et al. (1995). In SanchezLorenzo et al. (2008) sunshine duration for Western Europe increases from 1938 (earliest value of plot) until 1950.

\section{Conclusions}

We investigated annual mean DTR for the period 1950 until 2005 for 23 different countries and regions in and around Europe as well as Europe as a whole. A total of 16 out of these 23 regions as well as the European mean show a statistically significant period of decrease and a subsequent increase in DTR. Two additional regions (BeNeLux, Spain) show an increase, which however is not statistically significant in the multiple regression analysis. Of the remaining five regions, two (East Germany, Portugal) show no specific trend and three (Sweden, Baltic States, Ukraine) regions show a continuation of the decreasing trend. The trend analysis is limited by the lack of a standard homogeneity procedure and by the limited number of available measurement sites and their spatial distribution.

The connection between DTR, shortwave radiation and $\mathrm{SO}_{2}$ emissions has been qualitatively discussed with respect to a common trend reversal. The period of reversal of DTR from decrease to increase is in most cases in line with social and economic development as indicated by $\mathrm{SO}_{2}$-emissions or deposition, respectively. All reversals of DTR were shown to take place between 1965 and 1990. This is consistent with the change from decrease to increase of incoming shortwave radiation ("Global Dimming" to "Global Brightening"). Consequently, we conclude that the long-term trends in DTR are strongly affected by changes in incoming shortwave radiation, presumably largely influenced by direct and indirect effects of aerosol from sulphurous emissions.
This may suggest that in more regions around the globe DTR will increase if the surface solar radiation continues to increase on a widespread basis.

\section{Appendix A}

\section{A1 Illustrative example how to read Table 1}

The example of Denmark, (Table 1, line 5) reads as follows: the first column contains the name of the region. The second column contains the $R^{2}$ between the time series and the best fitted trend of the form:

$f(x)=f_{1} * x+f o$

Following the $R^{2}$ a small "o" indicates that the linear coefficient is statistically significant above the $90 \%$ level or in more common words: it is $90 \%$ likely that the linear coefficient cannot be zero if the time series should be represented by the given equation. Column three contains again the value for the $R^{2}$. However, now the comparison is performed between the time series of annual mean DTR of Denmark and the best fit of the type:

$f(x)=f_{2} * x^{2}+f_{1} * x+f o$

Following this $R^{2}$ two lines of coding symbols contain the information that the linear coefficient $\left(f_{1}\right)$ is now $99 \%$ significant (two " $x$ ") and the quadratic trend is different from zero at the $95 \%$ significance level (one " $x$ "). For the third order polynomial, shown in the fourth column, the $R^{2}$ increases again to now 0.3 . The three lines of symbols following the $R^{2}$ indicate that the cubic coefficient is now significant at the 99\% level, the quadratic at the $95 \%$ level but the linear coefficient misses the $90 \%$ level and is marked consequently with a small "-". In the 5 th column the $R^{2}$ increases to 0.33 thus explaining already $33 \%$ of the given annual mean time series. However the polynomial of the form,

$f(x)=f_{4} * x^{4}+f_{3} * x^{3}+f_{2} * x^{2}+f_{1} * x+f o$

overestimates for the given time period.

\section{A2 Explanatory example Fig. 4}

The method underlying Fig. 4 can be illustrated comparing Figs. 2f (Denmark) and 2o. The highest value for the seven year running mean during the given period for FRY appears in 1991 with $9.8^{\circ} \mathrm{C}$, the lowest is $8.98^{\circ}$ in 1977 . The absolute difference is $0.82^{\circ} ; 10 \%$ of $0.82^{\circ}$ is $0.082^{\circ}$. Consequently all years with a seven year running mean value of the time series of FRY within the range of $8.98^{\circ}$ and $9.06^{\circ}$ have been marked with a dash in Fig. 4, line $6(1975,1976,1978)$. These dashes consequently give a sort of error bar for the calculated year of reversal. For the reversal in the annual mean time series of Denmark, a much bigger uncertainty range is given, namely between 1981 and 1987. The highest value in the period 1965 
to 1995 of the seven year running mean of the annual means from Denmark is $5.75^{\circ}$ (1970) the lowest is $5.21^{\circ}$ (1981). So the difference between the two extremes is $0.54^{\circ}$ which is only two thirds of FRY difference. This fact gives credit to the different overall variability of the investigated time series. After adding $10 \%$ of $0.54^{\circ}$ to the minimum of $5.21^{\circ}$ all years within the range of $5.21^{\circ}$ to $5.26^{\circ}(1982-1987)$ are marked with a dash (Fig. 4, line 14).

\section{Appendix B}

\section{Addititonal, detailed information on the regional annual means}

\section{B1 Western Europe}

Norway. The mean DTR, predominantly governed by stations around $60^{\circ} \mathrm{N}$, shows an increase during the $1950 \mathrm{~s}$ followed by a significant decrease until the late 1980s. Starting in 1987 DTR increases, but is then interrupted by a dip around 2000 (Fig. 2a). This dip reduces the significance of the fitted polynomial, still the third and forth order polynomials are significant above $90 \%$.

Sweden. The averaged time series for Sweden shows a highly significant negative linear trend (Fig. 2b). The selected stations are all located south of $64^{\circ} \mathrm{N}$, representing southern Sweden (Fig. 3). The DTR appears to level off since the late 1980s. However, when reducing the Swedish data to cover only stations for the period until 2005, a tendency to an increase became apparent, this trend was not significant in any model. Also the selection would have given even more weight to the most southern part of Sweden.

Finland. The data for Finland consists of three stations, evenly divided from north to south, namely Helsinki, Jyvaskyla and Sodankyla. The national trend is best represented by a second order polynomial trend significant above the $99 \%$ level (Fig. 2c).

Denmark. Though one of the smaller countries, Denmark contributes 5 equally distributed stations to the dataset (Fig. 3). The best fitting trend model is the third order polynomial (Fig. 2f). The second and third order coefficients are significant at $95 \%$ level, whereas the linear term shows only p-value of 0.18 corresponding to approximately $80 \%$ confidence level.

Great Britain. Only three stations met the demanded quality requirements of temporal coverage up to 2003, namely Oxford, Wick and Waddington. The former two are located in the industrialized southern area of the UK and show a distinct DTR reversal from decrease to increase. Wick is situated at the northern tip of the British mainland showing a general decrease. Despite this the fitted second order polynomial is significant at the $95 \%$ level, indicating a trend from decrease to increase (Fig. 2e). An early reversal around 1965 is visible from the 7-year running-mean.

BeNeLux. Belgium and Luxembourg each contribute only one station to the selected dataset, hence they were analyzed together with the seven stations from the Netherlands. The analysis of the BeNeLux region showed no significant trend. The best fit however is a second order polynomial with p-values around 0.23 (Fig. $2 \mathrm{~m}$ ). The seven year running mean trend shows an overall increase since 1980 .

East Germany. No significant trend is apparent. Best fit is the second order polynomial (Fig. 2j). P-values are in general above 0.7 (confidence level, below 30\%) in all models and coefficients.

West Germany. For the mean of the 13 stations a distinct reversal from decrease to increase is visible in the national mean time series. Consequently the second order polynomial trend is significant at the $95 \%$ level in both coefficients (Fig. 2i).

France. The 25 selected stations are distributed equally over France (Fig. 3). Similar to West Germany the second order polynomial is significant at the $95 \%$ level emphasizing the DTR development form decrease to increase with the reversal period between 1965 and 1985 .

Alpine Region. There are only two stations, one from Austria and one from Switzerland. Most Swiss stations had to be rejected due to homogeneity issues. Problems were caused by change of location and instrumentation. The only Swiss station that met the quality requirements is BaselBinningen. For Austria only one station (Kremsmuenster) with complete data coverage from 1950 to 2005 is provided in ECA\&D-P. The mean trend derived from the two stations is best described by a polynomial of the second order (Fig. 2n). The main contribution to this shape is given by the Basel-Binningen station which shows a distinct decrease and increase.

Italy. The mean trend for Italy is calculated from four stations. The best fitting polynomial is second order (Fig. 2t). Overall a strong decrease and subsequent increase is visible.

Spain. For Spain a slight decrease in the seven year running mean up to 1977 is visible. Thereafter an equally slightly visible increase in DTR can be seen (Fig. 2r). However, the statistical analysis shows no significant trend on the $90 \%$ confidence level. The p-values for Spain are, 0.36 for the linear and 0.22 for the cubic coefficient. 
Portugal. A total of three stations are sufficient according to the demanded quality requirements .Braganca shows an overall increase for the whole period while Lisboa (Lisbon) and Porto show a continuous decrease in DTR (Fig. 2q).

\section{B2 Eastern Europe}

Former Republic of Yugoslavia. The reliable period for the FRY region is from 1956 to 2004 . The best fitting trend model for that time series is a fourth order polynomial trend with p-values below 0.05 for all coefficients. Consequently the development shows more than a single period of decrease and increase. From 1956 to about 1965 the DTR increases this is followed by a distinct decrease up to around 1980 . From 1980 until 1990 a second and more emphasized increase is dominant with a subsequent phase of more or less constant development until 2004 (Fig. 20). However, the most pronounced feature in this period is the decrease and then subsequent increase in DTR from 1965 to 1991.

Romania. The best fit is a third order polynomial with p-values of about 0.03 for the first and second coefficient, the p-value for the third coefficient is slightly higher with 0.051 and therefore misses the $95 \%$ confidence boundary. From the seven year running mean a period with a distinct decrease from 1961 to 1971 is visible, followed by a longer period of increasing DTR lasting until 1990, subsequently the running mean shows a constant development (Fig. 2p).

Czechoslovakia. As for the area of the FRY, the former Czechoslovakian states are best fitted by a fourth order polynomial (Fig. 2k). All tested coefficient of the fourth order polynomial are above the 95\% significance level (p-values < 0.05). The decreasing period lasts until 1977 according to the seven year running mean, then the DTR increases until it stops around 1992. This is followed by a stable to slightly decreasing period until 2004.

Poland. Only two stations with data from 1966 to 2005 are available, Leba and Siedlce these both show very similar long-term trends. The best fit is a second order polynomial. p-values for the coefficients are 0.083 and 0.046. For Poland a decreasing period is visible from 1966 to 1980 and an increasing period from 1986 to 2005 (Fig. 2g).

Baltic Region. A strong increase is visible in the seven year running mean up to 1966 , followed by a decrease, leveling off in 1991. A short increase starting in 1990 come to an end by 1996 and then becomes a continued decrease (Fig. 2h). The result of this is an overall linear decrease in the fitted trend model significant at $95 \%$ level.

Ukraine. The nearly monotonic drop of the Ukrainian mean DTR lasts over the whole period from 1951 to 2005
(Fig. 21). The linear trend is significant above 99\%. The two most westerly located stations, L'Vov (Lwiw/Lemberg) and Uzhgorod show a dominant increase since the middle of the 1970s. For the two biggest cities of Ukraine, Khrakov and Kyiv (Kiev) a decrease in DTR until the mid-1990s is dominant follow by a leveling off or increase thereafter.

Russia. The largest region of the so called Eastern-European section is the European part of Russia with Brest (Brestzonalnaya) as only representative station for Belarus included. The mean DTR development for the overall 36 stations is best described by a third order polynomial. p-values are around 0.001 the $R^{2}$ is 0.22 . Assuming that none of the high frequency is caught by the polynomial this is a quite high value. The seven year running mean describes an increase until 1966 followed by a continuous decrease until 1992 and thereafter an equally uninterrupted increase until 2003 (Fig. 2d).

\section{B3 Surrounding regions}

Iceland. The best fit for the DTR time series is the third order polynomial (Fig. 2u). All coefficients are above 95\% significant. Equal to Denmark and Finland, Iceland is considered to be a mixture of the Western and Eastern European trend type.

Turkey. The shape of the mean data series of the three stations is best described by a third order polynomial. The seven year running mean describes a distinct increase from 1950 until 1963, then a subsequent decrease is disturbed by a short period of increase between 1974 and 1984, thereafter the long-term decrease is continued until 1990. Finally an increase until 2004 is visible from the smoothed 7 year running-mean curve. The described interruption causes a reduction in the significance of the trend model, p-values are 0.150 (1st), 0.053 (2nd) and 0.027 (3rd). When smoothing the described period the p-values are: 0.03 (2nd) and 0.009 (3rd). The linear coefficient never becomes statistically significant since there is no overall decrease or increase in the series.

Algeria. Three stations are available which are distributed roughly evenly along a north south transect (Fig. 3). All stations, namely Alger-Dar el Beida, El Golea and Tamanrasset, present a similar trend best described with a third order polynomial. The significance of coefficient is above the $99 \%$ level. The seven year running mean is dominated by an increase from 1950 to 1963 , followed by a decrease lasting until 1986. Finally, an increase can be noted up to 2004. The peek in 2001 is a prominent feature of the mean and can be equally found in each of the contributing stations. 
Acknowledgements. We would like to thank Royal Netherlands Meteorological Institute for access to the ECAD-P data set and the meteorological services of Romania (Sorin Cheval), Norway (Elin Lundstad, Eirik Forland, Knut A. Iden) and Iceland (Trausti Jonsson) for providing additional data. Discussions with Thomas Peter, Jörg Mäder and Andreas Roesch were highly appreciated. Paul Southern's proofreading is very gratefully acknowledged. The work was funded by ETH Zurich, Polyproject: "Variability of the sun and global climate" - Phase II. MW and AO acknowledge NCCR Climate funded by the Swiss National Science Foundation.

Edited by: J. Quaas

\section{References}

Abakumova, G. M., Feigelson, E. M., Russak, V., and Stadnik, V. V.: Evaluation of long-term changes in radiation, cloudiness, and surface temperature on the territory of the former Soviet Union, J. Climate, 9, 1319-1327, 1996.

Alpert, P., Kishcha, P., Kaufman, Y. J., and Schwarzbard, R.: Global dimming or local dimming? Effect of urbanization on sunlight availability, Geophys. Res. Lett., 32, L17802, doi:10.1029/2005GL023320, 2005.

Beer, J., Mende, W., and Stellmacher, R.: The role of the sun in climate forcing, Quaternary Sci. Rev., 19, 403-415, 2000.

Berge, E., Bartnicki, J., Olendrzynski, K., and Tsyro, S. G.: Longterm trends in emissions and transboundary transport of acidifying air pollution in Europe, J. Environ. Manage., 57, 31-50, 1999.

Braganza, K., Karoly, D. J., and Arblaster, J. M.: Diurnal temperature range as an index of global climate change during the twentieth century, Geophys. Res. Lett., 31, L13217, doi:10.1029/2004g1019998, 2004.

Dai, A., DelGenio, A. D., and Fung, I. Y.: Clouds, precipitation and temperature range, Nature, 386, 6626, 665-666, 1997.

Dai, A., Trenberth, E., and Karl, T. R.: Effects of clouds, soil moisture, precipitation, and water vapour on diurnal temperature range, J. Climate, 12, 2451-2473, 1999.

De Bruin, H. A. R., van den Hurk, B. J. J. M., and Welgraven, D.: A series of global radiation at Wageningen for 1928-1992, Int. J. Climatol., 15, 1253-1272, 1995.

Easterling, D. R., Horton, B., Jones, P. D., Peterson, T. C., Karl, T. R., Parker, D. E., Salinger, M. J., Razuvayev, V., Plummer, N., Jamason, P., and Folland, C. K.: Maximum and minimum temperature trends for the globe, Science, 277, 364-367, 1997.

Englehart, P. J. and Douglas, A. V.: Changing behavior in the diurnal range of surface air temperatures over Mexico, Geophys. Res. Lett., 32, L01701, doi:10.1029/2004g1021139, 2005.

Gilgen, H., Wild, M., and Ohmura, A.: Means and Trends of shortwave Irradiance at the surface estimated from global energy balance archive data, J. Climate, 11, 2042-2061, 1998.

Gilgen, H., Roesch, A., Wild, M., and Ohmura, A.: Decadel changes in shortwave irradiance at the surface estimated from Global Energy Balance Archive data, in review, 2008.

Karl, T. R., Kukla, B., and Gavin, J.: Decreasing diurnal temperature range in the United States and Canada from 1941 through 1980, J. Clim. Appl. Meteorol., 23, 1489-1504, 1984.
Karl, T. R., Jones, P. D., Knight, R. W., Kukla, G., Plummer, N., Razuvayev, V., Gallo, K. P., Lindseay, J., Charlson, R. J., and Peterson, T. C.: Asymmetric trends of daily maximum and minimum temperature, B. Am. Meteorol. Soc., 74, 1007-1023, 1993.

Klein Tank, A. M. G., Wijngaard, J. B., Können, G. P., Böhm, R., Demarée, G., Gocheva, A., Mileta, M., Pashiardis, S., Hejkrlik, L., Kern-Hansen, C., Heino, R., Bessemoulin, P., MüllerWestermeier, G., Tzanakou, M., Szalai, S., Pálsdóttir, T., Fitzgerald, D., Rubin, S., Capaldo, M., Maugeri, M., Leitass, A., Bukantis, A., Aberfeld, R., van Engelen, A. F. V., Forland, E., Mietus, M., Coelho, F., Mares, C., Razuvaev, V., Nieplova, E., Cegnar, T., Antonio López, J., Dahlström, B., Moberg, A., Kirchhofer, W., Ceylan, A., Pachaliuk, O., Alexander, L. V., and Petrovic, P.: Daily dataset of 20th-century surface air temperature and precipitation series for the European Climate Assessment, Int. J. Climatol., 22, 1441-1453, doi:10.1002/Joc.773, 2002.

Klein, H. and Benedictow, A.: EMEP MSC-W (Meteorological Synthesizing Centre-West) Data Note 1/2006: Transboundary data by main pollutants $\left(\mathrm{S}, \mathrm{N}, \mathrm{O}_{3}\right)$ and PM, ISSN 1890-0003, 2006.

Kukla, G. and Karl, T. R.: Nighttime warming and the GreenhouseEffect, Environ. Sci. Technol., 27, 8, 1468-1474, 1993.

Lefohn, A. S., Husar, J. D., Husar, R. B., and Brimblecombe, P.: Assessing historical global sulfur emission patterns for the period 1850-1990, Report number: DOE/ER/30234-1, prepared for the US department of energy, 190 pp. [NTIS DE96014790], 1996.

Liepert, B. G. and Kukla, G. J.: Decline in global solar radiation with increased horizontal visibility in Germany between 1964 and 1990, J. Climate, 10, 2391-2401, 1997.

Liu, B., Xu, M., Henderson, M., and Gong, W.: A spatial analysis of pan evaporation trends in China 1955-2000, J. Geophys. Res., 109, D15102, doi:10.1029/2004jd004511, 2004.

Mishchenko, M. I., Geogdzhayev, I. V., Rossow, W. B., Cairns, B., Carlson, B. E., Lacis, A. A., Liu, L., and Travis, L. D.: Longterm satellite record reveals likely recent aerosol trend, Science, 315, 1543, doi:10.1126/science.1136709, 2007.

Mylona, S.: Sulphur dioxide emissions in Europe 1880-1991 and their effect on sulphur concentrations and depositions, Tellus, 48, 662-689, 1996.

Norris, J. R. and Wild, M.: Trends in aerosol radiative effects over Europe inferred from observed cloud cover, solar "dimming" and solar "brightening", Geophys. Res. Lett., 112, D08214, doi:10.1029/2006JD007794, 2007.

Ohmura, A. and Lang, H.: Secular variations of global radiation in Europe, IRS'88: Current problems in atmospheric radiation, edited by: Leonoble, J. and Geleyn, J. F., A. Deepak Publ., Hampton, VA, 298-301, 1989.

Ohmura, A.: Observed long-term variations of solar irradiance at the earth's surface, Space Sci. Rev., 125, 111-128, doi:10.1007/s11214-006-9050-9, 2006.

Pinker, R. T., Zhang, B., and Dutton, E. G.: Do satellites detect trends in surface solar radiation?, Science, 308, 850-854, doi:10.1126/science.1103159, 2005.

Robock, A. and Li, H.: Solar dimming and $\mathrm{CO}_{2}$ effects on soil moisture trends, Geophys. Res. Lett., 33, L20708, doi:10.1029/2006g1027585, 2006.

Roderick, M. L. and Farquhar, G. D.: The cause of decreased pan evaporation over the past 50 years, Science, 298, 1410-1411, 2002. 
Sanchez-Lorenzo, A., Brunetti, M., Calbo, J., and Martin-Vide, J.: Recent spatial and temporal variability and trends of sunshine duration over the Iberian Peninsula from a homogenized dataset, J. Geophys. Res., 112, D20115, doi:10.1029/2007jd008677, 2007.

Sanchez-Lorenzo, A., Calbó, J., and Martin-Vide, M.: Spatial and temporal trends in sunshine duration over Western Europe (1938-2004), J. Climate, doi:10.1175/2008JCLI2442.1, in press, 2008.

Stanhill, G. and Cohen, S.: Global dimming: a review of the evidence for widespread and significant reduction in global radiation with discussion of its probable cause and possible agricultural consequences, Agr. Forest Meteorol., 107, 255-278, 2001.

Stanhill, G. and Cohen, S.: Solar radiation changes in the United States during the Twentieth Century: Evidence from sunshine measurements, J. Climate, 18, 1503-1512, 2005.

Stechikov, G. L. and Robock, A. : Diurnal asymmetry of climatic response to increased $\mathrm{CO}_{2}$ and aerosol: forcings and feedbacks, J. Geophys. Res., 100(D12), 26 211-26 227, 1995.

Stern, D. I.: Reversal of the trend in global anthropogenic sulphur emissions, Global Environ. Change, 16, 207-220, doi:10.1016/j.gloenvcha.2006.01.001, 2006.

Stone, D. A. and Weaver, A. J.: Factors contributing to diurnal temperature range trends in twentieth and twenty-first century simulations of the CCCma coupled model, Clim. Dynam., 20, 435445, doi:10.1007/s00382-002-0288-y, 2002.

Smith, S. J., Pitcher, H., and Wigley, T. M. L.: Future sulphur dioxide emissions, Clim. Change, 73, 267-318, doi:10.1007/s10584005-6887-y, 2005.
Streets, D. G., Wu, Y., and Chin, M.: Two-decadel aerosol trends as a likely explanation of the global dimming/brightening transition, Geophys. Res. Lett., 33, L15806, doi:10.1029/2006GL026471, 2006.

Trenberth, K. E., Jones, P. D., Ambenje, P., Bojariu, R., Easterling, D., Klein Tank, A., Parker, D., Rahimzadeh, F., Renwick, J. A., Rusticucci, M., Soden, B., and Zhai, P.: Observations: Surface and Atmospheric Climate Change. The Physical Science Basis, Contribution of Working Group I to the Fourth Assessment Report of the Intergovernmental Panel on Climate Change, edited by: Solomon, S., Qin, D., Manning, M., Chen, Z., Marquis, M., Averyt, K. B., Tignor, M., and Miller, H. L., 987 pp., 2007.

Vestreng, V., Myhre, G., Fagerli, H., Reis, S., and Tarrasón, L.: Twenty-five years of continuous sulphur dioxide emission reduction in Europe, Atmos. Chem. Phys., 7, 3663-3681, 2007, http://www.atmos-chem-phys.net/7/3663/2007/.

Vose, R. S., Easterling, D. R., and Gleason, B.: Maximum and minimum temperature for the globe: An update through 2004, Geophys. Res. Lett., 32, L23822, doi:10.1029/2005GL024379, 2005.

Wild, M., Gilgen, H., Roesch, A., Ohmura, A., Long, C. N., Dutton, E. G., Forgan, B., Kallis, A., Russak, V., and Tsvetkov, A.: From dimming to brightening, Science, 308, 741-908, doi:10.1126/science.1103215, 2005.

Wild, M., Ohmura, A., and Makowski, K.: Impact of global dimming and brightening on global warming, Geophys. Res. Lett., 34, L04702, doi:10.1029/2006GL028031, 2007. 